DOI: 10.5272/jimab.2013191.372

Journal of IMAB - Annual Proceeding (Scientific Papers) 2013, vol. 19, book 1

\title{
ANALYSIS OF THE SUCCESS OF THIRD-YEAR STUDENTS OF MEDICINE IN MEDICAL UNIVERSITY - VARNA BY TESTED ON THE CARDIOVASCULAR SYSTEM
}

\author{
Kosta Mirchev ${ }^{1}$, Miroslav Marinov ${ }^{2}$, Iglika Marinova ${ }^{3}$, Borislav Boychev ${ }^{4}$, \\ Christiana Romanova ${ }^{5}$, Nina Radeva ${ }^{5}$, Radko Zl. Radev ${ }^{2}$ \\ 1Department of Physiology and Pathophysiology, \\ 2Department of Preclinical and Clinical Sciences, \\ 3Department of Health Management, \\ 4University Hospital - Varna, \\ 5Department of Hygiene and disaster medicine, \\ Medical University - Varna, Bulgaria.
}

\section{SUMMARY}

The test is objective, fast and convenient way to assess student's knowledge. When used regularly, it helps rhythmic learning of school material. Students of third course year are subjected in pathophysiology test of cardiovascular system during exercise. Follow the test results for the period from 2006 to 2012: Students show a relatively very good success. Differences in each individual years are negligible. Highlighting the advantages of this method of assessment. It is recommended a wider use of test as a mean as improving quality of training of students.

Key words: test, pathophysiology, success of students, cardiovascular system.

\section{INTRODUCTION:}

Over the past two or three decades there has been an increased use of testing of students $(1,2,3,4)$. The test as a form of assessment of student's knowledge has several advantages over other methods of testing: all are evaluated on equal footing, the subjective factor related to the examiner is minimized, can cover a large group of test simultaneously, allowing it to be subjected to inspection by other examiners, etc. $(5,6,7,8,9,10,11)$. In the Medical University of Varna required for examination of the student to have a documented written evaluation. In this sense, the test on paper is a good way to implement such a requirement. Pathophysiology of Varna has some experience on the test since 1983. Over the years, were issued two collections of tests for our students of Medicine and students from College of Medicine. Similar collections issue and other related departments of medical schools (12). In the literature, however, there is no data to shed light on the success of students tested by tests and the suitability of this method for evaluation (13). Therefore, we aimed to analyze the success of students from third medical course subjected to the test on the cardiovascular system.

\section{MATERIALAND METHODS:}

The study includes medical students from the third year for the period from 2006 to 2012 and covers about 20-30 $\%$ of students in each class. They are student groups, selected at random - an average of tree-five groups of each class. On each test is offered as a test question on target material of cardiovascular system. The question has proposed a different number of correct and incorrect answers. The questions in the test were of the "closed" i.e. the test should indicate the true (and) answer(s) proposed by the examiner. The students were declared that they would be examined in this way a week in advance. On the day of exercise on the material of cardiovascular system is implemented only test trial. Assistant facilitator explains the conditions for testing performance. The student knows that every marked wrong answer decreases its evaluation with two units. In two incorrect assessments answer is "weak". Time which students have to answer the question is three minutes. Examiners review and evaluate the performance of students during the time that they engage in practical work. At the end of the exercise were parsed the results and mistakes were corrected. Successful encouraged and made mistakes is urging greater diligence. 


\section{RESULTS:}

In Tabl. 1. and Fig. 1. are showed results from the test during different years.

Table 1. Test results of third-year students of Medicine in Medical University - Varna for years.

\begin{tabular}{|c|c|c|c|c|c|c|}
\hline Year & $\begin{array}{c}\text { Number of } \\
\text { groups }\end{array}$ & $\begin{array}{c}\text { Number of } \\
\text { students }\end{array}$ & $\begin{array}{c}\text { Number of } \\
\text { correct } \\
\text { answers in }\end{array}$ & $\begin{array}{l}\text { Number of } \\
\text { incorrect } \\
\text { answers in }\end{array}$ & $\begin{array}{l}\text { Number of } \\
\text { students } \\
\text { responding }\end{array}$ & $\begin{array}{c}\text { Average } \\
\text { evaluation } \\
\text { of student }\end{array}$ \\
\hline 2006 & 3 & 17 & 3 & 3 & 14 & 4.95 \\
\hline 2007 & 3 & 17 & 2 & 3 & 16 & 4.59 \\
\hline 2008 & 4 & 20 & 2 & 3 & 15 & 4.50 \\
\hline 2011 & 5 & 21 & 2 & 3 & 14 & 4.29 \\
\hline 2012 & 5 & 20 & 2 & 3 & 14 & 4.00 \\
\hline
\end{tabular}

Fig. 1. Test results of third course students of Medicine in Medical University - Varna for each years.

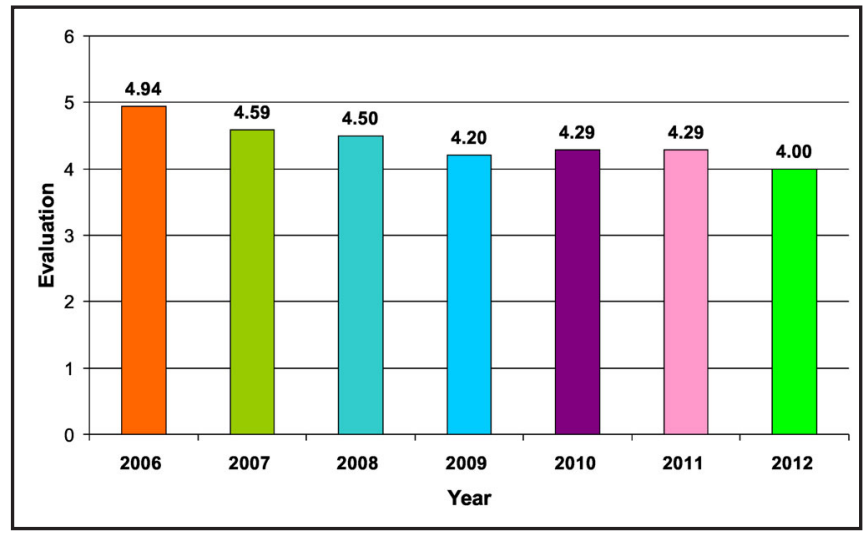

The table and figure show that comparing the results of the success of students during different years show similar results. Most students show a high success rate in $2006-$ 4.94, while the lowest those in 2012 - 4.00. However, differences are within the standard error. Analysis of the composition of students (subject of another study) shows that failures over the years are mostly foreign students in 2010 and 2011 are the most in seven each year. The change in the number of groups of students, their number and the number of correct and incorrect answers did not affect the number of students successfully answered.

\section{DISCUSSION:}

As everyone knows that the cardiovascular system is one of the most extensive and difficult to understand that the students (14). Lack of confidence in success in different years, although some tendency for reduction of success lately shows that the test showed an almost constant, though not of the highest level of preparedness according to this test. Given that the share of morbidity and mortality from cardiovascular disease is significant, the results achieved by students of knowledge could be considered as very good. It is no secret that many students prepare for exams only during exam period, which undoubtedly has a negative impact on their level of preparedness and quality of their education as relevant for the discipline and general as future physicians $(14,15)$. Therefore, any form of training, which could contribute to the rhythmic quality and training of relevant professionals, particularly doctors, is relevant and useful during the learning process $(1,16)$. The obtained data together with the advantages that gives the used test: objectivity, speed of evaluation and possible correction and / or filling of knowledge covering all students on equal terms for the evaluation tool for promoting regular training on the material, give basis for finding that this method of testing is appropriate and suitable. It could be applied in other nosological units of material studied, as well as other subjects. Inconvenience associated with the need to advance the development of test and time spent on checking evaluator are negligible compared to the merits of this method for assessing and improving the quality of education $(3,5,15)$.

\section{CONCLUSIONS:}

1. Test evaluation of medical students from third academic course unit cardiovascular system shows almost unchanged level over the years.

2. Students achieved good grades give reason to assume that they are prepared during the academic year studied section.

3. Test bench testing method felicitous way of achieving and maintaining rhythmic in the preparation of students in the school discipline. 


\section{REFERENCES:}

1. Cohen RJ, Swerdlik ME. Psychological Testing and Assessment: An introduction to tests and measurement. 7th ed. New York: McGraw Hill. 2010.

2. About the Joint Committee on Testing Practices. Code of Fair Testing Practices in Education. [http:// www.apa.org/science/programs/testing/ fair-testing.pdf].

3. Airasian P. Classroom Assessment: Concepts and Applications. 4nd ed. New York: McGraw Hill. 2000.

4. Hedges LV. An Exchange: Part I: Does Money Matter? A MetaAnalysis of Studies of the Effects of Differential School Inputs on Student Outcomes. Educ Res. 1994; 23 (3): 5-14. [ERIC]

5. Cangelosi J. Designing Tests for Evaluating Student Achievement. New York: Longman. 1989.

6. Gronlund NE, Waugh C. K. Assessment of Student Achievement. 9th ed. Boston: Allyn and Bacon. 2008.
7. Haladyna TM, Downing SM. Validity of a Taxonomy of MultipleChoice Item-Writing Rules. Appl Meas Educ. 1989; 2 (1): 51-78. [ERIC]

8. Monahan T. The Rise of Standardized Educational Testing in the U.S. - A Bibliographic Overview. Rensselaer Polytechnic Institute, Department of Science and Technology Studies. 1998.

9. Ravitch D. The Uses and Misuses of Tests. In: The Schools We Deserve. New York: Basic Books. 1985: pp. 172-181.

10. Wilson N. Educational standards and the problem of error. Education Policy Analysis Archives. 1997; 6 (10). [EPAA]

11. Vodenicharov C, Glutnikova Zl, Gateva A. Innovations in Medical Education. Sofia: Aquagrapics. 1997. [In Bulgarian].

12. Popov B, Atanasov P. Analysis of the success of the preclinical courses, studies and state examinations of Bulgarian students from the Medical
Faculty of Trakia University - Stara Zagora. Bulgarska medicina. 2003; 11 (1): 31-32. [In Bulgarian].

13. Campbell MJ, Machin D, Walters SJ. Medical Statistics: A Textbook for the Health Sciences. 4th ed. Chichester, UK; Hoboken, NJ: Wiley. 2007.

14. Vukanovic-Criley JM, Criley S, Warde CM, Boker JR, Guevara-Matheus L, Churchill WH, et al. Competency in cardiac examination skills in medical students, trainees, physicians, and faculty: a multicenter study. Arch Intern Med. 2006; 166 (6): 610-616. [PubMed].

15. Vodenicharov $\mathrm{C}$, Mitova $\mathrm{M}$. Pedagogical problems of medical education (Medical Education). Sofia: Graifc Consult.1998. [In Bulgarian].

16. Tzokeva Zh, Spasov V. Results from the study of pharmacology and clinical pharmacology of students training in the Medical Faculty of Trakia University - Stara Zagora. Bulgarska medicina. 2003; 11 (5): 27-30. [In Bulgarian].

\section{Corresponding author:}

Radko Zlatkov Radev, MD, PhD

Department of preclinical and clinical medicine, Medical University of Varna "Prof. P. Stoyanov" Tel: +359/52 677051

E-mail: pathophysiology@mu-varna.bg; 